$16^{\circ}$ USIHC - Congresso Internacional de Ergonomia e Usabilidade de USIHC Interfaces Humano Computador

CINAHPA

CINAHPA | 2017 - Congresso Internacional de Ambientes Hipermídia para Aprendizagem.

\title{
MODA INCLUSIVA: VESTUÁRIO PARA MULHERES COM PARAPLEGIA
}

\section{INCLUSIVE FASHION: CLOTHING FOR WOMEN WITH PARAPLEGIA}

\author{
Gabriela Bazzanella Lazarin ${ }^{1}$, Bela. em Moda. \\ Eliane Pinheiro ${ }^{2}$, M.Sc. \\ (1) Universidade Estadual de Maringá \\ e-mail: gabilazarin95@gmail.com \\ (2) Universidade Estadual de Maringá \\ e-mail: elianepinheirouem@hotmail.com
}

Palavras-chave: ergonomia, vestuário, paraplegia.

Este estudo tem como objetivo identificar as adequações ergonômicas necessárias para melhorar a vestibilidade e acessibilidade no vestuário para cadeirantes com paraplegia. Como metodologia utilizou-se a pesquisa bibliográfica e a pesquisa de campo. Os resultados mostram a importância da adequação do vestuário com conforto, acessibilidade e estética.

Key words: ergonomics, clothing, paraplegia.

This article aims to identify the required ergonomic adjustment to improve usability and accessibility in the clothing for paraplegics in wheelchairs. The methodology used was the bibliographical research and the field research. The results show the importance of suitability of clothing with comfort, accessibility and esthetics.

\section{Introdução}

É notório o quanto as questões que envolvem a moda estão em evidência ultimamente, principalmente em relação à inclusão de pessoas com deficiência na sociedade. Isso se deve ao fato de que elas possuem o direito e a necessidade de se vestirem com bom gosto, demonstrando sua personalidade através de produtos de moda. Entretanto, devido às modificações em seus corpos, torna-se difícil encontrar um vestuário que atenda e supra fielmente as necessidades de vestibilidade e conforto (WOLTZ; CARVALHO, 2008).

A ergonomia possui a função de ser aplicada para o público cadeirante com paraplegia a fim de possibilitar adequações no vestuário que visam a autoestima, o conforto e qualidade de vida do mesmo. Deste modo, os estudos ergonômicos são importantes para entender a anatomia corporal de uma pessoa que passa a maior parte do tempo na posição sentada. Isto implica diretamente no modo como deve ser elaborado um produto de moda, em relação a sua modelagem e matéria-prima
Realização:
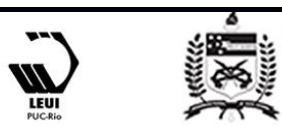


\section{$16^{\circ}$ \\ ERGODESIGN USIHC CINAHPA}

(SANTOS, 2014).

Dados estatísticos brasileiros do Censo de 2010, mostram que 45.606 .048 pessoas $(23,9 \%$ da população total) possuem pelo menos algum tipo de deficiência, seja visual, auditiva, motora ou intelectual. Dentro dessa porcentagem, $7 \%$ da população brasileira possui a deficiência motora/física (OLIVEIRA, 2012). Os dados servem como comprovação de que este público consumidor existe e necessita de uma inclusão social em todos os segmentos, principalmente em relação aos produtos de vestuário.

Deste modo, o trabalho tem como objetivo geral pesquisar e entender os conceitos ergonômicos, os fatores que levam a deficiência física, a paraplegia e os pontos críticos da vestibilidade de modo a desenvolver produtos de vestuário que tragam conforto, acessibilidade e autoestima ao seu usuário. Como resposta a estas questões, busca-se entender, por meio de questionários aplicados ao público, as reais necessidades e desejos do consumidor.

\section{A paraplegia e uma relação com o uso da cadeira de rodas}

Segundo Lianza e Sposito (1994), para a locomoção de um paraplégico a cadeira de rodas é indispensável, representando um equipamento essencial para a independência e para a reintegração social do indivíduo. Uma cadeira de rodas deve proporcionar as seguintes qualidades: estabilidade, segurança, acessibilidade, leveza, maleabilidade e conforto. Quando há uma boa posição para o cadeirante, este consegue maximizar seu nível funcional e aumentar suas possibilidades de interagir com o ambiente. De acordo com os autores anteriormente citados, os movimentos básicos em uma cadeira de rodas são: manipular o freio, remover o apoio dos braços, pegar objetos no chão, alcançar o apoio dos pés e levantar as nádegas do assento.

Inicialmente, o paciente se encontra inseguro e tem preferência por um equipamento que proporcione estabilidade. Quando o quadro da lesão evolui, uma cadeira de rodas leve e com melhor $16^{\circ}$ Ergodesign - Congresso Internacional de Ergonomia e Usabilidade de Interfaces Humano Tecnológica: Produto, Informações Ambientes Construídos e Transporte

$16^{\circ}$ USIHC - Congresso Internacional de Ergonomia e Usabilidade de Interfaces Humano Computador

CINAHPA | 2017 - Congresso Internacional de Ambientes Hipermídia para Aprendizagem. desempenho deve ser prescrita, nunca deixando de atender as reais necessidades do paciente. Em relação a estrutura, as cadeiras podem ser de aço (são resistentes e pesadas), alumínio (são resistentes, com peso menor e maior custo) ou de fibras sintéticas (são menos resistentes, mais leves e com custo elevado). Acessórios que permitam ajustes personalizados são importantes para o conforto do paciente, como apoios de braços, apoios reguláveis para os pés, freios para frente e para trás, protetores de roupas, protetores de aros, rodas com diâmetro maior e cintos. Afim de maximizar benefícios para o usuário, o profissional terapeuta precisa analisar o peso da cadeira, sua estabilidade ou instabilidade quando este está sentado, a distribuição do peso corporal, o nível de atrito, a temperatura da almofada em relação a pele, o preço e os desejos do paciente (BRASIL, 2013).

Conforme relata Iida (2005), a posição sentada necessita do dorso e do ventre como atividade muscular. Deste modo, a pele que cobre o osso ísquio encontrada nas nádegas, suporta a maior parte do peso do corpo. Em relação a posição horizontal, o consumo de energia é de 3 a $10 \%$ maior. Todo o peso do tronco (superior a bacia) é suportado pelo assento da cadeira, aliviando a força dos membros inferiores do corpo. Os ossos denominados tuberosidades isquiáticas são revestidos por uma camada fina de tecido muscular e uma pele grossa que suporta grandes pressões, estes são importantes para compreender a posição sentada, pois estão situados na bacia.

De acordo com Huet e Moraes (2003), mesmo que a posição sentada pareça confortável, depois de um tempo torna-se incômoda e desconfortável devido a imobilização, alteração da coluna vertebral e da pelve. As mudanças de posição aliviam a pressão sobre as tuberosidades isquiáticas (ossos mais próximos do assento) melhorando a circulação sanguínea. Por uma consequência da gravidade, a gordura e os tecidos musculares começam a se deslocar de forma lenta e acabam deixando os ossos pressionarem a derme.

A pele começa a necrosar quando não há variação de posição (a queimação é o primeiro indício) e
Realização:

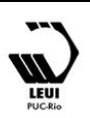




\section{$16^{\circ}$ \\ ERGODESIGN USIHC CINAHPA}

aumenta a sensação de dor. Outro aspecto fisiológico analisado pelas autoras é a maior angulação da coluna lombar. Após 30 minutos na posição sentada, o tecido que envolve os vasos sanguíneos diminui de espessura inibindo a circulação, há um aumento de ácido lático nos músculos e de água no tecido subcutâneo. As medidas para melhorar o conforto são: adquirir um assento com área maior de apoio e realizar movimentos ativos (HUET; MORAES, 2003).

\subsection{Características físicas, fisiológicas e emocionais}

Aquarone (2013) afirma que após uma lesão medular é comum o paciente desenvolver dor crônica, sendo caracterizada como dor neuropática central e pode surgir depois de semanas, meses ou anos após o trauma. Uma das explicações para esta dor, é que o tecido lesionado tenta se regenerar pelo fenômeno da neuroplasticidade, como não consegue, surge uma cicatriz chamada neuroma no lugar da lesão, causando uma dor constante e mais comum em membros inferiores.

Grave (2004) explica que a paralisia motora ocorre com uma lesão na coluna anterior. Os músculos paralisados acabam sendo deformados, mas nem sempre há perda da sensibilidade. De acordo com a autora, uma sequela incapacitante e muito comum para quem passou por um traumatismo raquimedular, é a espasticidade que compromete o sistema nervoso central. Esta é definida como um fenômeno motor involuntário, ou seja, quando há movimentação ativa ou passiva do músculo. $\mathrm{O}$ reflexo, com sua função dinâmica, tem relação com este sistema de espasticidade, e quando não funciona bem, causa posturas anormais à pessoa com deficiência.

De acordo com Venturini et al. (2006), pessoas com lesão medular possuem sua mobilidade física prejudicada, influenciando no autocuidado para banho/higiene, para vestir-se/arrumar-se e para higiene íntima. Devido a lesão, há alteração na eliminação de dejetos fecais e urinários, podendo causar constipação, incontinência intestinal e urinária. Além disso, há alteração na percepção sensorial que pode causar dor aguda e reflexo tátil $16^{\circ}$ Ergodesign - Congresso Internacional de Ergonomia e Usabilidade de Interfaces Humano Tecnológica: Produto, Informações Ambientes Construídos e Transporte

$16^{\circ}$ USIHC - Congresso Internacional de Ergonomia e Usabilidade de Interfaces Humano Computador

CINAHPA | 2017 - Congresso Internacional de Ambientes Hipermídia para Aprendizagem. modificado. Outros problemas físicos observados são: a presença de úlceras por pressão (são lesões localizadas na pele ou epiderme), infecção urinária, bexiga neurogênica (é uma disfunção urinária) e deformidades. Vale ressaltar que nem sempre os cadeirantes possuem todos os problemas apontados anteriormente, um caso é diferente do outro.

Segundo Coelho (2002), o sofrimento afeta o físico e o psíquico do ser humano, alterando seu comportamento de maneira profunda, pois este se vê em uma situação de estar dependente de outro. O sofrimento pode ser físico ou emocional, o primeiro, afeta o organismo humano devido às lesões sofridas. Já o segundo, afeta a mente do indivíduo, podendo causar problemas de relacionamento e de desequilíbrio emocional.

De acordo com Silva et al. (2012), uma boa readaptação do indivíduo com lesão medular depende de como este encara a sua nova condição de vida. Além disso, a reabilitação deve ser iniciada com rapidez por uma equipe multiprofissional que consiga melhorar as capacidades funcionais e reinseri-lo de forma rápida na comunidade visando sua qualidade de vida, que engloba tanto os aspectos físicos quanto os psicológicos.

Amaral (2009) complementa explicando o fenômeno da adaptação, que inclui: a resposta emocional à nova situação, as dificuldades, $o$ suporte, a consciência da situação, a organização dos recursos e a adaptação para encontrar um novo sentido da vida. A resposta emocional indica como o indivíduo vai avaliar a nova circunstância passando pela fase de impacto que gera emoções negativas. Na fase pós-impacto surgem emoções positivas, como o sentimento de gratidão (no sentido de aceitar a nova vida) e de aceitação (demonstrando bem-estar e calma). As dificuldades estão relacionadas à transformação que o corpo sofre tanto fisicamente, quanto psicologicamente, socioeconomicamente e espiritualmente.

O suporte emocional vem para ajudar o paciente a lidar com as adversidades enfrentando os desafios. O suporte espiritual também é importante, pois muitos encontram na religião uma razão maior 


\section{$16^{\circ}$ \\ ERGODESIGN USIHC CINAHPA}

para continuar a viver. Deste modo, a real adaptação para encontrar um novo sentido da vida, ocorre após a situação ter sido analisada e compreendida, escolhendo a integração física, psicológica e social (AMARAL, 2009).

\subsection{A ergonomia e sua relação com o vestuário}

Inicialmente, a ergonomia se aplicava exclusivamente à indústria e na relação homem/máquina. Atualmente, tornou-se bem mais ampla e abrange estudos sobre sistemas complexos de interação entre homem/máquina/materiais na realização de um trabalho. Sua expansão atingiu praticamente todos os tipos de atividades humanas. Com a ergonomia, o trabalho que exigia esforço físico passou a ser deixado de lado, visando agora os aspectos cognitivos ou intelectuais (IIDA, 2005).

Segundo Iida (2005), a ergonomia é definida como o estudo da adaptação do trabalho ao homem, envolvendo toda a situação em que ocorre um relacionamento entre o homem e uma atividade produtiva. Além disso, engloba o planejamento e o projeto, o controle e a avaliação, deste modo, abrangendo o antes, o durante e o depois de um trabalho. Com este conceito, torna-se necessário estudar primeiramente as características do trabalhador para em seguida projetar a atividade que ele consegue realizar, sempre cuidando da sua saúde e bem-estar. É de suma importância priorizar o conhecimento humano adaptando-o sempre às suas capacidades e possíveis limitações.

Ainda de acordo com Iida (2005), a ergonomia possui características específicas em seu sistema. A primeira é a Ergonomia Física, que inclui a anatomia, antropometria, fisiologia e biomecânica, tem relevância na escolha da postura correta, no manejo de materiais, nos movimentos repetitivos, nos possíveis distúrbios do músculo, na segurança e saúde do operário. Já a segunda, é a Ergonomia Cognitiva, onde prioriza os processos mentais na tomada de decisões, na interação do homem com a tecnologia, dos momentos de estresse e nos treinamentos, valorizando a percepção, a memória, o raciocínio e a resposta motora do trabalhador. $16^{\circ}$ Ergodesign - Congresso Internacional de Ergonomia e Usabilidade de Interfaces Humano Tecnológica: Produto, Informações Ambientes Construídos e Transporte

$16^{\circ}$ USIHC - Congresso Internacional de Ergonomia e Usabilidade de Interfaces Humano Computador

CINAHPA | 2017 - Congresso Internacional de Ambientes Hipermídia para Aprendizagem.

Por último, a Ergonomia Organizacional, que inclui a busca por aprimorar os sistemas sócio técnicos envolvendo a organização, a política e os processos, objetivando a comunicação, o projeto, a programação, a participação, a colaboração e a qualidade do trabalho.

Deste modo, entende-se que a ergonomia influencia no desempenho de um sistema de produção, buscando sempre priorizar os recursos humanos do trabalhador, como sua saúde, segurança e satisfação. A eficiência não deve ser o centro dos objetivos na visão da ergonomia, mas deve ser consequência de um bom planejamento, de uma boa organização e de um bom trabalho.

Além da influência no desempenho de um sistema de produção, a ergonomia também estuda o corpo humano, seus movimentos e a interação deste com o meio externo, fatores estes que se relacionam com o vestuário. Partindo da ideia de que o vestuário é importante à vida humana, a ergonomia está voltada às necessidades do ser humano, incluindo as de proteção corporal.

Neste sentido, Santos (2014) aborda os conceitos de ergonomia à área do vestuário com algumas questões pertinentes: como será feita a roupa (qual tecido e qual modelagem) e quem é o usuário (seu biótipo e possíveis problemas). Desta forma, é um desafio adaptar as roupas ao usuário oferecendo conforto, mobilidade, caimento e segurança.

Martins (2008), afirma que a roupa é a segunda pele do ser humano devido ao fato de que está em contato com a epiderme na maior parte do tempo. A autora relata que o vestir e despir estão mais fáceis, pois os produtos de moda atendem a índices ergonômicos. A propriedade de facilidade de manutenção relacionada à área em questão inclui no vestuário: lavar, passar, retirar manchas e repor aviamentos. Em relação à propriedade ergonômica da segurança, as roupas devem atender às necessidades de movimento, como de sentar, levantar, abaixar e esticar. A usabilidade aplicada à moda possibilita a utilização eficaz do produto de vestuário, tornando-o agradável por meio do conforto térmico e da estética. 


\section{$16^{\circ}$ \\ ERGODESIGN USIHC CINAHPA}

\section{Metodologia}

Para a coleta de dados foi elaborado um questionário composto por dois blocos. O primeiro, voltado para conhecer o público alvo e o segundo para auxiliar no desenvolvimento do produto. Contém questões fechadas e abertas totalizando 49 perguntas. Para aplicação utilizou-se uma plataforma online e o link foi disponibilizado por meio de uma rede social no período de 17 a 21 de maio de 2016.

As respondentes totalizaram 23 mulheres com paraplegia, residentes em território nacional. Buscou-se com as questões identificar dados pessoais (como idade, onde residem e profissão), dificuldades e sintomas resultantes da lesão medular sofrida, bem como informações sobre o comportamento de compra das roupas, gostos pessoais, tendências de moda que seguem e o que um vestuário deve possuir para suprir seus desejos, ou seja, conhecer e entender as necessidades e dificuldades do público-alvo, a fim de desenvolver produtos de vestuário que atendam o perfil do mesmo. Os dados coletados foram tabulados com auxílio do software Excel.

\section{Análise e discussão dos dados}

Conforme Woltz e Carvalho (2008), a inclusão social de cadeirantes é impulsionada positivamente através da moda e do vestuário. Para que isso aconteça, são necessários estudos e adequações ergonômicas sobre o corpo humano e uma verdadeira aproximação com o público-alvo. Deste modo, objetivando a participação destes na sociedade e aumentando sua autoestima, torna-se possível desenvolver um vestuário inclusivo que siga tendências de moda e facilite o cotidiano das pessoas com deficiência por meio de adaptações estratégicas (como tecidos confortáveis e aberturas nos modelos). A Tabela 1 mostra que 57\% das respondentes sentem dificuldade em encontrar roupas que se adequem bem ao seu corpo, representando a maioria. Entende-se que é necessário projetar um vestuário adequado ao corpo que sofreu modificações devido ao uso da cadeira de rodas. Sendo que a modificação mais frequente constatada foi à atrofia das pernas que $16^{\circ}$ Ergodesign - Congresso Internacional de Ergonomia e Usabilidade de Interfaces Humano Tecnológica: Produto, Informações Ambientes Construídos e Transporte

$16^{\circ}$ USIHC - Congresso Internacional de Ergonomia e Usabilidade de Interfaces Humano Computador

CINAHPA | 2017 - Congresso Internacional de Ambientes Hipermídia para Aprendizagem. resulta na perda significativa de massa muscular.

Tabela 1: O usuário e o vestuário \begin{tabular}{lr} 
Questões & {$[\%]$} \\
\hline $\begin{array}{l}\text { 1. Referente à dificuldade em encontrar roupas que se } \\
\text { adequem ao corpo }\end{array}$ & 57 \\
$\begin{array}{l}\text { 2. Referente ao uso da cadeira de rodas no dia-a-dia } \\
\text { 3. Referente à percepção de modificação corporal }\end{array}$ & 100 \\
\hline
\end{tabular}

Fonte: Autoria própria (2016)

Os autores afirmam que na posição sentada na cadeira de rodas, percebe-se principalmente um encurtamento e alargamento do tronco, alargamento dos quadris, achatamento e alargamento das coxas, os joelhos e cotovelos ficam flexionados constantemente. Essas alterações físicas são extremamente importantes para entender e adaptar uma modelagem de forma correta e ergonômica ao público em questão (WOLTZ; CARVALHO, 2008). Constatou-se que as participantes fazem uso da cadeira de rodas em seu cotidiano (100\% das respondentes). Deste modo, entende-se que o uso da cadeira de rodas pode interferir na maneira como o produto de moda deve ser projetado, buscando solucionar possíveis dificuldades encontradas em um vestuário comum.

De acordo com Grave (2004), ajustes nas roupas do público em questão são fundamentais, pois estas não aderem ao corpo. Além disso, devem esconder aparelhos como órteses ou próteses a fim de aumentar a autoestima de seu usuário. A autora afirma que é preciso "ler" o corpo modificado pela lesão, analisando e aproximando suas diferenças da normalidade, buscando soluções saudáveis ao físico e ao psicológico. Com a presente pesquisa, verificou-se que as respondentes perceberam alguma modificação em seu corpo devido ao uso frequente da cadeira de rodas que resulta na permanência da posição sentada. A grande maioria (91\%) assinalou a opção sim, enquanto apenas $9 \%$ disseram que não. Assim, entende-se que as roupas devem possuir modelagens e matérias-primas que
Realização:
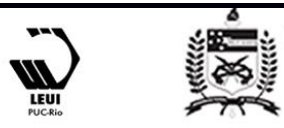


\section{$16^{\circ}$ \\ ERGODESIGN USIHC CINAHPA}

se adequem ao corpo modificado facilitando seu cotidiano com conforto.

Para as que responderam sim (21 respondentes), a questão seguinte referia-se à: quais regiões corporais que apresentam maior modificação. Nesta questão, a respondente poderia escolher mais de uma opção. As pernas foram a maioria representando $30 \%$ do total, em razão ao fato de que com o passar do tempo vão perdendo massa muscular pela imobilidade. Em seguida, abdômen e nádegas com porcentagem igual de $18 \%$ cada. $\mathrm{E}$ por fim, braços e costas com $17 \%$ cada. Entende-se as roupas devem ser projetadas para se adequar ao corpo atendendo às modificações percebidas pelas respondentes.

A modelagem das peças deve acompanhar as mudanças dos planos e eixos do corpo que alteram o equilíbrio, e integrar as particularidades da sequela de lesão sofrida. Grave (2004) ainda diz que as vestimentas que proporcionam estética, conforto e qualidade de vida afetam de forma positiva o emocional por meio da autoconfiança. Algumas adaptações no vestuário realçadas pela autora em seus estudos são: o uso de entretelas adequadas, enchimentos, duplicidade de tecido, fechos e abotoamentos de boa qualidade, elásticos, velcros, recortes estratégicos e tecidos com bom caimento e elasticidade. De acordo com a presente pesquisa, constatou-se que os acessórios presentes nas roupas que incomodam as respondentes são: o zíper com $23 \%$, as etiquetas com $17 \%$, botões (13\%), bojo (10\%), ilhós (9\%), cordão/fitas (8\%), velcro e costuras com $6 \%$ cada. As opções menos escolhidas foram estampas em relevo com $4 \%$, bordados e elástico com $2 \%$ cada. As respostas confirmam que o uso de velcro e elástico são boas opções para atender as necessidades das usuárias proporcionando praticidade às roupas.

Matarazzo (2009, apud MAFFEI, 2010) complementa que as roupas dos cadeirantes devem ser feitas com tecidos leves como algodão e viscose, não devem ser apertadas ou justas, e devese projetar a peça com um ou dois números maiores na área do quadril e da cintura. Quanto à matéria-prima têxtil que está em contato direto com a pele, $61 \%$ das respondentes preferem malha.
Em seguida foi indicado o jeans/sarja com 39\%, o que mostra a preferência por tecidos maleáveis e confortáveis.

Somado a isto, outros pontos devem ser levados em consideração de acordo com Maffei (2010): nas calças os bolsos devem ser posicionados em cima da perna por uma questão de funcionalidade, alças nas laterais da calça facilitam o vestir, ganchos maiores proporcionam conforto, camisetas curtas não devem ser usadas, pois podem causar machucados devido ao atrito do corpo com a cadeira de rodas e saias ou vestidos rodados fazem volume e podem atrapalhar.

Maffei (2010) também relata que o excesso de recortes e de costuras é inviável, os tecidos devem absorver suor e não causar alergias, o excesso de tecido pode enroscar nas rodas das cadeiras, apliques emborrachados (como alguns tipos de estampas) causam desconforto térmico, devem-se evitar botões, zíperes, bordados e tecidos pesados como o jeans. No vestuário, o conforto é de extrema importância para a satisfação do usuário. A mesma autora explica que o conforto físico inclui a sensação do tecido em contato com a pele e da confecção da peça em relação à modelagem, construção e acabamento do produto. O conforto fisiológico refere-se às questões termorreguladoras. O conforto psicológico relaciona-se à aparência, estética, meio social e cultural que o usuário está inserido.

Lessa, Silveira e Barreto (2016) relatam que as matérias-primas de tecidos de algodão ou fibra de bambu, por serem naturais, favorecem a transpiração da pele. É importante essa questão, pois cadeirantes que fazem tarefas com os membros superiores do corpo podem ter suor excessivo. Tecidos de malha com viscose e tecidos planos com elastano também são boas opções que favorecem conforto e maleabilidade. Além disso, já em relação aos acessórios, as espumas casca de ovo, que criam um aspecto almofadado, são ótimas para evitar úlceras de pressão (lesões na pele) em cadeirantes que possuem sensibilidade nos membros.

Auler e Lopes (2012) citam outras adequações
Realização:

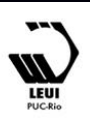




\section{$16^{\circ}$ \\ ERGODESIGN USIHC CINAHPA}

ergonômicas para o público evidenciado: uso de manga removível para a questão do conforto térmico; regiões almofadadas em blusas na parte das costas e em calças na parte traseira, pois entram em contato direto com a cadeira de rodas; ilhós que acomodam fones de ouvido (bom para manter o acessório preso à peça de roupa, gerando segurança por não enroscar em qualquer parte da cadeira de rodas); aberturas totais laterais nas peças para facilitar o vestir e despir; aberturas estratégicas para quem precisa carregar medicamentos ou sondas externas.

Neste mesmo sentido, Wang et al. (2014) afirmam que um novo design de vestuário que facilite as atividades do cotidiano pode ajudar a reduzir a tensão física, a carga de trabalho dos ajudantes dos usuários da cadeira de rodas e ainda a melhorar sua autoestima. A necessidade principal das respondentes em relação ao vestuário é o conforto, de acordo com 39\% das participantes. A opção variedade de modelos e cores visando a estética correspondem a $35 \%$, seguido de adaptações nas roupas para facilitar o cotidiano com $26 \%$. As opções cobrir o corpo e esconder aparelhos auxiliares não foram escolhidas. Esta questão confirma a necessidade de roupas confortáveis que envolvam modelagem, materiais têxteis e estética adequados.

Assim, entende-se que aliar os aspectos e conceitos ergonômicos a um produto de moda proporciona benefícios aos cadeirantes. Os benefícios são o conforto, a estética atrativa seguindo tendências, a segurança, autoconfiança, autoestima, e principalmente, $\mathrm{o}$ atendimento as necessidades físicas e fisiológicas geradas pela lesão sofrida. Por fim, confirmando todos os pontos expostos acima, a Figura 1 mostra que para a maioria das respondentes um vestuário adequado às suas necessidades deve possuir tecidos confortáveis $(22 \%)$ e seguir tendências de moda $(22 \%)$. $16^{\circ}$ Ergodesign - Congresso Internacional de Ergonomia e Usabilidade de Interfaces Humano Tecnológica: Produto, Informações Ambientes Construídos e Transporte

$16^{\circ}$ USIHC - Congresso Internacional de Ergonomia e Usabilidade de Interfaces Humano Computador

CINAHPA | 2017 - Congresso Internacional de Ambientes Hipermídia para Aprendizagem.

Figura 1 - Referente a um vestuário adequado às necessidades

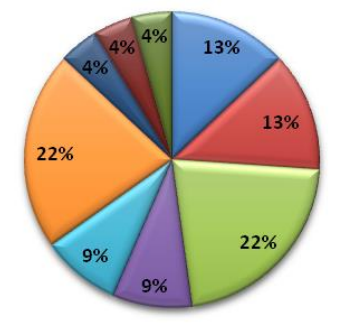

$\begin{array}{ll}\square \text { Roupas com fácil abertura para vestir/despir } & \square \text { Roupas com folga para não apertar } \\ \square \text { Tecidos confortáveis } & \square \text { Roupas adaptadas/práticas } \\ \square \text { Calças com elástico no cós } & \square \text { Roupas que seguem tendências de moda } \\ \square \text { Roupas que vistam bem no corpo } & \square \text { Roupas que disfarcem aparelhos auxiliares } \\ \square \text { Roupas que não marquem o abdômen } & \end{array}$

Fonte: Autoria própria (2016)

As outras características escolhidas foram: fácil abertura para vestir/despir e roupas com folga para não apertar, correspondendo a $13 \%$ cada opção. Calças com elástico no cós e roupas adaptadas/práticas representam $9 \%$ cada. Estes resultados auxiliam no entendimento das necessidades das usuárias permitindo conhecer as características de como deve ser um vestuário adequado a partir do ponto de vista do público em questão.

\section{Conclusões}

A moda é um fator de extrema importância para a qualidade de vida dos seres humanos, pois influencia diretamente na sua relação com a sociedade por meio da aparência visual. Consequentemente, a saúde emocional também é alterada devido ao fato da moda ter como característica relevante a possibilidade de aumentar a autoestima de seu usuário quando este veste roupas que lhe agradam e que o façam se sentir bem.

Com a pesquisa e o levantamento teórico sobre a deficiência física, paraplegia, ergonomia, a posição sentada, acessibilidade e a moda inclusiva, pode-se constatar que existe uma lacuna no mercado referente à produtos de vestuário que atendam de forma satisfatória as necessidades de funcionalidade, praticidade e estética das mulheres 


\section{$16^{\circ}$ \\ ERGODESIGN USIHC CINAHPA}

$16^{\circ}$ Ergodesign - Congresso Internacional de Ergonomia e Usabilidade de Interfaces Humano Tecnológica: Produto, Informações Ambientes Construídos e Transporte

$16^{\circ}$ USIHC - Congresso Internacional de Ergonomia e Usabilidade de Interfaces Humano Computador

CINAHPA | 2017 - Congresso Internacional de Ambientes Hipermídia para Aprendizagem. com paraplegia. Os dados coletados permitiram compreender e conhecer os problemas enfrentados pelo público em relação ao vestuário usado no diaa-dia.

Deste modo, os produtos foram desenvolvidos levando em consideração a vestibilidade, funcionalidade e a estética. As peças possuem a facilidade de vestir ou despir por meio de adaptações estratégicas, como recortes frontais com velcro, uso de elásticos, botões com ímã, comprimentos mídis, peças de cintura alta que não apertam e que valorizam o corpo feminino. Em relação aos materiais têxteis, foram selecionados aqueles com elasticidade e maleabilidade priorizando o conforto, como as malhas com fibras de algodão e viscose.

Outra questão relevante que foi analisada em entrevistas com o público, foi a vontade das mulheres em se sentirem bonitas, satisfeitas com a sua aparência e ao mesmo tempo confortáveis, vestindo roupas que sigam as tendências de moda atuais, que fujam do básico e que possam proporcionar autonomia para poderem se vestir sozinhas.

Por fim, verifica-se que o presente trabalho proporciona a inclusão social por meio dos produtos de vestuário com conteúdo de moda. Somado a isso, serve como base para estudos futuros e aprofundados em relação à moda inclusiva para mulheres com paraplegia. Todas as pessoas com algum tipo de deficiência precisam ser incluídas e integradas na sociedade e a moda é um meio fundamental para atingir este objetivo, facilitando o cotidiano das pessoas e melhorando sua autoestima.

\section{BIBLIOGRAFIA}

AMARAL, Maria Teresa Mendonça Pinto. Encontrar um novo sentido da vida: um estudo explicativo da adaptação após lesão medular. Portugal: 2009.

AQUARONE, Rita Lacerda. Dor neuropática: implicações na qualidade de vida de pessoas com lesão medular. Dissertação (Mestrado) - Escola de Enfermagem da Universidade de São Paulo. São Paulo: 2013. 98 p.

AULER, Daniela; LOPES, Juliana (orgs.). Moda Inclusiva: perguntas e respostas para entender o tema. São Paulo: SEDPcD, 2012.

\section{BRASIL. Diretrizes de Atenção à Pessoa com \\ Lesão Medular. Ministério da Saúde, Secretaria de Atenção à Saúde, Departamento de Ações Programáticas Estratégicas e Departamento de Atenção Especializada. Brasília: Ministério da Saúde, 2013. 68 p.}

COELHO, Maria das Graças. Aspectos do Deficiente Físico e o Valor do Sofrimento. Florianópolis: Papa-Livro, 2002. 135 p.

GRAVE, Maria de Fátima. A modelagem sob a ótica da ergonomia. São Paulo: Zennex

Publishing, 2004.

HUET, Mariana; MORAES, Anamaria de. Medidas de pressão sob a pelve na postura sentada em pesquisas de ergonomia. Rio de Janeiro: 2003.

IIDA, Itiro. Ergonomia: Projeto e Produção. $2^{\mathrm{a}}$ ed. São Paulo: Blucher, 2005.

LESSA, Analívia; SILVEIRA, Carina; BARRETO, Carol. Moda socialmente correta: a ergonomia aplicada às roupas das deficientes cadeirantes. Salvador: 2016.

LIANZA, Sergio; SPOSITO, Maria Matilde de Mello. Reabilitação: a locomoção em pacientes com lesão medular. São Paulo: SARVIER:

Associação Paulista de Medicina, 1994.

MAFFEI, Simone Thereza Alexandrino. O produto de moda para o portador de deficiência física: análise de desconforto. Dissertação (Mestrado) - Universidade Estadual Paulista "Júlio de Mesquita Filho", Bauru: 2010.

MARTINS, Suzana Barreto. Ergonomia e moda: repensando a segunda pele. In PIRES, Dorotéria 


\section{$16^{\circ}$ \\ ERGODESIGN USIHC CINAHPA}

$16^{\circ}$ Ergodesign - Congresso Internacional de Ergonomia e Usabilidade de Interfaces Humano Tecnológica: Produto, Informações Ambientes Construídos e Transporte

$16^{\circ}$ USIHC - Congresso Internacional de Ergonomia e Usabilidade de Interfaces Humano Computador

CINAHPA | 2017 - Congresso Internacional de Ambientes Hipermídia para Aprendizagem.

Baduy (org.). Design de Moda: olhares diversos. Barueri, SP: Estação das Letras e Cores Editora, 2008.

OLIVEIRA, Luiza Maria Borges. Cartilha do Censo 2010: Pessoas com Deficiência. Brasília: SDH-PR/SNPD, 2012. 32 p.

SANTOS, Cristiane de Souza dos. O corpo. In SABRÁ, Flávio (org.). Modelagem: tecnologia em produção de vestuário. Rio de Janeiro: SENAI CETIQT; São Paulo: Estação das Letras e Cores, 2014. $158 \mathrm{p}$.

SILVA, Gelson Aguiar da; SCHOELLER, Soraia Dornelles; GELBCKE, Francine Lima;

CARVALHO, Zuíla Maria Figueiredo de; SILVA, Evelise Maria de Jesus Paula da. Avaliação funcional de pessoas com lesão medular: utilização da escala de independência funcional MIF. Florianópolis: 2012.

VENTURINI, Daniela Aparecida; DECESARO, Maria das Neves; MARCON, Sonia Silva. Conhecendo a história e as condições de vida de indivíduos com lesão medular. Porto Alegre: 2006.

WANG, Yunyi; WU, Daiwei; ZHAO, Mengmeng; LI, Jun. Evaluation on an ergonomic design of functional clothing for wheelchair users. In Applied Ergonomics. China: 2014.

WOLTZ, Silvia; CARVALHO, Michel Ângelo Fernandes. Vestuário inclusivo: a adaptação do vestuário às pessoas com necessidades especiais. In: $8^{\circ}$ Colóquio de Moda, Anais, Rio de Janeiro, 2008. 